\title{
Global patterns of stream detritivore distribution: implications for biodiversity loss in changing climates
}

\author{
Luz Boyero ${ }^{1,2 *}$, Richard G. Pearson², David Dudgeon³ , Verónica Ferreira ${ }^{4}$, \\ Manuel A. S. Graça ${ }^{4}$, Mark O. Gessner ${ }^{5,6} \dagger \ddagger$, Andrew J. Boulton ${ }^{7}$, \\ Eric Chauvet ${ }^{8,9}$, Catherine M. Yule ${ }^{10}$, Ricardo J. Albariño ${ }^{11}$, Alonso Ramírez ${ }^{12}$, \\ Julie E. Helson ${ }^{13}$, Marcos Callisto ${ }^{14}$, Muthukumarasamy Arunachalam ${ }^{15}$, \\ Julián Chará ${ }^{16,17}$, Ricardo Figueroa ${ }^{18}$, Jude M. Mathooko ${ }^{19}$, \\ José F. Gonçalves $\mathrm{Jr}^{14} \S$, Marcelo S. Moretti ${ }^{14}$, Ana Marcela Chará-Serna ${ }^{16,20}$, \\ Judy N. Davies ${ }^{7}$, Andrea Encalada, ${ }^{4,21}$, Sylvain Lamothe ${ }^{8,9}$, \\ Leonardo M. Buria ${ }^{11}$, José Castela ${ }^{4}$, Aydeé Cornejo ${ }^{22,23}$, Aggie O. Y. Li $^{3}$, \\ Charles M’Erimba ${ }^{19}$, Verónica Díaz Villanueva ${ }^{11}$, María del Carmen Zúñiga ${ }^{16}$, \\ Christopher M. Swan ${ }^{24}$ and Leon A. Barmuta ${ }^{25}$
}

${ }^{1}$ Wetland Ecology Department, Doñana Biological Station-CSIC, Avda Americo Vespucio s/n, 41092 Sevilla, Spain, ${ }^{2}$ School of Marine and Tropical Biology, James Cook University, Townsville, QLD 4811, Australia, ${ }^{3}$ School of Biological Sciences, The University of Hong Kong, Hong Kong SAR, China, ${ }^{4} I M A R-C M A$ and Department of Life Sciences, University of Coimbra, 3001-401 Coimbra, Portugal, ${ }^{5}$ Department of Aquatic Ecology, Eawag: Swiss Federal Institute of Aquatic Science and Technology, Überlandstrasse 133, 8600 Dübendorf, Switzerland, ${ }^{6}$ Institute of Integrative Biology (IBZ), ETH Zurich, 8092 Zurich, Switzerland, ${ }^{7}$ Ecosystem Management, School of Environmental and Rural Science, University of New England, Armidale, NSW 2350, Australia, ${ }^{8}$ Université de Toulouse, UPS, INPT; EcoLab (Laboratoire d'Écologie Fonctionnelle), 29 Rue Jeanne Marvig, F-31055 Toulouse, France, ${ }^{9}$ CNRS, EcoLab, F-31055 Toulouse, France, ${ }^{10}$ School of Science, Monash University, Jalan Lagoon Selatan, Bandar Sunway, 46150, Selangor Malaysia, ${ }^{11}$ Laboratorio de Limnología, INIBIOMA, Universidad Nacional del Comahue-CONICET, Quintral 1250, 8400, Argentina, ${ }^{12}$ Institute for Tropical Ecosystem Studies, University of Puerto Rico, PO Box 70377, San Juan, PR 00936, USA, ${ }^{13}$ Surface and Groundwater Ecology Research Group, Department of Biological Sciences, University of Toronto at Scarborough, 1265 Military Trail, Toronto, ON, Canada M1C1A4, ${ }^{14}$ Laboratório de Ecologia de Bentos, Instituto de Ciências Biológicas, Universidade Federal de Minas Gerais, CP 486, CEP 30.161-970, Belo Horizonte, MG, Brazil, ${ }^{15}$ Sri Paramakalyani Centre for Environmental Sciences, Manonmainam Sundaranar University, Alwarkuruchi, Tamil Nadu 627 412, India, ${ }^{16}$ Centro para la Investigación en Sistemas Sostenibles de Producción Agropecuaria, CIPAV, Carrera 25 no. 6-62, Cali, Colombia, ${ }^{17}$ Centro de Investigaciones y Estudios en Biodiversidad y Recursos Genéticos, CIEBREG, POB 97, Pereira, Colombia, ${ }^{18}$ Aquatic Systems Research Unit, Environmental Science Center EULAChile, University of Concepción, PO Box 160-C, Concepción, Chile, ${ }^{19}$ Department of Biological Sciences, Egerton University, PO Box 536, Egerton, Kenya, ${ }^{20}$ Departamento de Biología, Grupo de Investigaciones Entomológicas, Universidad del Valle, Apartado Aéreo 25360, Cali, Colombia, ${ }^{21}$ Colegio de Ciencias Biológicas y Ambientales, Universidad San Francisco de Quito, Campus Cumbayá, PO BOX 17-1200-841, Quito, Ecuador, ${ }^{22}$ Programa Centroamericano de Maestría en Entomología, University of Panama, Estafeta Universitaria, Apdo. 3366, Panama City, Panama, ${ }^{23}$ Sección de Entomología, Instituto Conmemorativo Gorgas de Estudios de la Salud, Avenida Justo Arosemena \& Calle 35, 0816-02593 Panama City, Panama, ${ }^{24}$ Department of Geography and Environmental Systems, University of Maryland, Baltimore County, Baltimore, MD 21250, USA, ${ }^{25}$ Freshwater Ecology Group, School of Zoology, University of Tasmania, Private Bag 5, Hobart, Tasmania 7001, Australia

\section{ABSTRACT}

Aim We tested the hypothesis that shredder detritivores, a key trophic guild in stream ecosystems, are more diverse at higher latitudes, which has important ecological implications in the face of potential biodiversity losses that are expected as a result of climate change. We also explored the dependence of local shredder diversity on the regional species pool across latitudes, and examined the influence of environmental factors on shredder diversity.

Location World-wide (156 sites from 17 regions located in all inhabited continents at latitudes ranging from $67^{\circ} \mathrm{N}$ to $41^{\circ} \mathrm{S}$ ).

Methods We used linear regression to examine the latitudinal variation in shredder diversity at different spatial scales: alpha (a), gamma (g) and beta (b) diversity. We also explored the effect of g-diversity on a-diversity across latitudes with regression analysis, and the possible influence of local environmental factors on shredder diversity with simple correlations.

Results Alpha diversity increased with latitude, while g- and b-diversity showed no clear latitudinal pattern. Temperate sites showed a linear relationship between g- and a-diversity; in contrast, tropical sites showed evidence of local species saturation, which may explain why the latitudinal gradient in a-diversity is not accompanied by a gradient in g-diversity. Alpha diversity was related to several local habitat characteristics, but g- and b-diversity were not related to any of the environmental factors measured.

Main conclusions Our results indicate that global patterns of shredder diversity are complex and depend on spatial scale. However, we can draw several conclusions that have important ecological implications. Alpha diversity is limited at tropical sites by local factors, implying a higher risk of loss of key species or the whole shredder guild (the latter implying the loss of trophic diversity). Even if regional species pools are not particularly species poor in the tropics, colonization from adjacent sites may be limited. Moreover, many shredder species belong to cool-adapted taxa that may be close to their thermal maxima in the tropics, which makes them more vulnerable to climate warming. Our results suggest that tropical streams require specific scientific attention and conservation efforts to prevent loss of shredder biodiversity and serious alteration of ecosystem processes.

\section{Keywords}

Detritus, diversity, guild, latitudinal gradient, leaf litter, shredders, species richness, stream ecosystems, trophic diversity.

*Correspondence: Luz Boyero, Wetland Ecology Department, Doñana Biological Station-CSIC, Avda Americo Vespucio s/n, 41092 Sevilla, Spain.

E-mail: luz.boyero@ebd.csic.es

†Present address: Department of Stratified Lakes, Leibniz Institute of Freshwater Ecology and Inland Fisheries (IGB), Alte Fischerhütte 2, 16775 Stechlin, Germany.

$\ddagger$ Present address: Department of Ecology, Berlin Institute of Technology (TU Berlin),

Ernst-Reuter-Platz 1, 10587 Berlin, Germany.

§Present address: Laboratório de Limnologia, Departamento de Ecología, IB, Universidade de Brasília, CEP 70910-900, Brasília, DF, Brazil.

ๆPresent address: Centro Universitário Vila Velha, Programa de Pós Graduação em Ecología de Ecosistemas, 29102-770, Vila Velha, ES, Brazil. 



\section{INTRODUCTION}

Ecologists have long been interested in global patterns of biodiversity because they seek to explain the general increase in species richness from the poles to the tropics. Numerous explanations for this gradient have been proposed (e.g. Willig et al., 2003; Mittelbach et al., 2007), and it has been demonstrated that such explanations need to consider the relationship between local and regional diversity. This relationship is not necessarily linear (Caley \& Schluter, 1997), as there may be a limit to the number of species that can be supported at a particular site (saturation), but different species assemblages may be found at different sites, thereby leading to higher regional diversity (e.g. Sale, 1977).

Hillebrand (2004) showed that diversity gradients are consistent across most taxa, habitats and spatial scales. However, his meta-analysis was based on species presence-absence data, which are insufficient for investigating ecological processes in which relative abundance of species play a major role (Dangles \& Malmqvist, 2004). Also of great ecological significance can be the number of species within particular guilds or trophic levels (Gessner et al., 2010). When species richness within a given trophic level is low, losing one or more species is likely to have particularly severe consequences at the ecosystem level (Duffy, 2009; Dudgeon \& Gao, 2010). This is because the chances of different species being functionally redundant (i.e. having similar effects on ecosystem processes) are lower with low diversity, and thus the loss of key species (Mills et al., 1993) is more likely. Moreover, the risk of losing an entire trophic level increases with decreasing species richness, potentially leading to a major reduction in trophic diversity (Hillebrand \& Matthiessen, 2009). Reducing the number of trophic levels within an ecosystem strongly affects ecosystem functioning by constraining ecosystem processes (e.g. organic matter decomposition or primary production) and changing the magnitude and efficiency of trophic transfer (Duffy et al., 2007).

Gradients of diversity within guilds or trophic levels are, however, virtually unknown. Here we explore global diversity patterns in stream shredders, a key detritivore guild in forest streams, where terrestrially derived detritus is the major energy and carbon source (Wallace et al., 1997). Shredders are able to assimilate carbon and other nutrients from this dead organic matter and associated microbes, and to convert a portion of it to animal tissue; they increase the rate at which coarse detritus is transformed into fine detritus; promote food availability for collectors and filter feeders; and thus play a fundamental role in organic matter decomposition and nutrient cycling (Cummins et al., 1973; Short \& Maslin, 1977; Wallace et al., 1982; Wallace \& Webster, 1996; Graça, 2001; Hieber \& Gessner, 2002). Although shredders belong to the same trophic level as other detritivores, they occupy a different position in the detritus processing chain, as they specialize in the primary processing of whole leaves rather than depending on processed, fragmented detritus (Heard, 1994).

Various local studies suggest that shredder diversity may be greater in temperate regions (see Boyero et al., 2009). This would imply that tropical streams might be more vulnerable to the loss of key species, or of the entire shredder guild to which shredders importantly contribute, with important consequences for ecosystem functioning. Furthermore, climate warming might be expected to exacerbate this effect, as most shredders belong to cool-adapted taxa and are possibly at the margin of their upper temperature tolerance in the tropics (Dillon et al., 2010). Studies of shredder diversity over broad spatial scales are, however, lacking, and global studies have shown that different stream taxa can exhibit different diversity patterns at both the local and regional scales (Vinson \& Hawkins, 2003; Pearson \& Boyero, 2009). Strong relationships between regional and local species richness have been demonstrated in Finland (Heino et al., 2003) and Australia (Marchant et al., 2006), suggesting that assemblages are unsaturated and indicating the importance of large-scale processes, but not denying the possible influence of local factors (e.g. water chemistry) on the regional diversity.

We examined shredder diversity across latitudes at a global scale (156 sites from 17 regions located in all inhabited continents at latitudes ranging from $67^{\circ} \mathrm{N}$ to $\left.41^{\circ} \mathrm{S}\right)$. Given the scale dependence of estimates of diversity (Gaston, 2000; Rahbek, 2005), and bearing in mind that local processes and relationships can be of great importance in determining species richness (Heino, 2009), we examined shredder species richness at both the local and regional scales (a- and g-diversity, respectively), as well as the change in assemblage composition among sites within regions (b-diversity). We hypothesized that shredder diversity would increase with latitude, on the basis of local studies reporting low numbers of shredder species in tropical streams (Boyero et al., 2009). We also explored the dependence of a-diversity on the regional species pool (i.e. g-diversity) across latitudes, hypothesizing that the relationship would be positive, although we had no a priori expectation regarding the shape of such a relationship. Finally, given that in a global study of this type local factors might mask any general relationships, we examined the influence of local environmental factors on shredder diversity.

\section{MATERIALS AND METHODS}

\section{Field and laboratory work}

We sampled shredders and their food resources (leaf litter) at 117 sites from a total of 13 regions, in Africa (one region), Asia (three regions), Australia (one region), Central America (two regions), Europe (two regions) and South America (four regions) (Table 1, Fig. 1), using the same methodology. The surveys were conducted between 2006 and 2007, during periods when leaf litter was present in the stream, and within a short period of time in each region to minimize intra-regional seasonal effects. In each region we sampled nine sites, each located in a different headwater stream with no notable human impact. Stream width was $\breve{S} 10 \mathrm{~m}$ and site length was approximately 10 times the stream width (50-100 m). 
Table 1 Study regions (including acronyms), range of latitude and altitude of sites, observed and estimated (first-order jackknife estimator; Palmer, 1990) regional diversity (g), and efficiency of sampling in estimated proportion of species collected.

\begin{tabular}{|c|c|c|c|c|c|c|}
\hline Region & Acronym of region & Latitude & $\begin{array}{l}\text { Altitude } \\
\text { (m a.s.l.) }\end{array}$ & Observed g & Estimated g & $\begin{array}{l}\text { Efficiency } \\
(\%)\end{array}$ \\
\hline & \multicolumn{6}{|l|}{ Main regions } \\
\hline Argentina (Nahuel Huapi National Park) & ARG & $40.46-41.25^{\circ} \mathrm{S}$ & $795-1465$ & 11 & 12.8 & 86 \\
\hline Brazil (Minas Gerais) & BRL & $18.05-20.50^{\circ} \mathrm{S}$ & $740-1320$ & 3 & 3.0 & 100 \\
\hline Colombia (western Andean region) & COL & $04.71-04.89^{\circ} \mathrm{N}$ & $950-2560$ & 12 & 12.0 & 100 \\
\hline Costa Rica (La Selva Biological Station) & CRA & $10.41-10.44^{\circ} \mathrm{N}$ & $30-100$ & 2 & 2.0 & 100 \\
\hline Ecuador (montane Andean forest) & ECD & $00.09-00.13^{\circ} \mathrm{S}$ & $1167-1380$ & 14 & 17.6 & 80 \\
\hline France (Montagne Noire) & FRN & $43.39-43.49^{\circ} \mathrm{N}$ & 320-1107 & 10 & 10.0 & 100 \\
\hline Hong Kong & $\mathrm{HKN}$ & $22.28-22.44^{\circ} \mathrm{N}$ & $70-370$ & 8 & 8.9 & 90 \\
\hline India (southern Western Ghats) & IND & $08.01-10.50^{\circ} \mathrm{N}$ & $225-450$ & 7 & 7.9 & 89 \\
\hline Kenya (various regions) & KEN & $00.02-00.37^{\circ} \mathrm{S}$ & $1713-2296$ & 2 & 2.9 & 69 \\
\hline Malaysia (various regions) & MLY & $00.03-04.42^{\circ} \mathrm{N}$ & 55-1993 & 22 & 24.3 & 91 \\
\hline Panama (Campana and Soberanía National Parks) & PAN & $08.68-09.17^{\circ} \mathrm{N}$ & 74-666 & 2 & 2.0 & 100 \\
\hline Portugal (Lousã and Caramulo Mountains) & PTG & $40.07-40.60^{\circ} \mathrm{N}$ & $113-814$ & 14 & 17.6 & 80 \\
\hline \multirow[t]{2}{*}{ Queensland (Australian wet tropics) } & QLD & $17.15-19.00^{\circ} \mathrm{S}$ & $40-880$ & 15 & 17.7 & 85 \\
\hline & \multicolumn{6}{|l|}{ Additional regions } \\
\hline Chile (Bio Bio region) & CHL & $36.88-38.00^{\circ} \mathrm{S}$ & $18-878$ & 3 & 4.6 & 65 \\
\hline Maryland (Appalachian Plateau) & MLD & $39.36-39.71^{\circ} \mathrm{N}$ & $483-842$ & 13 & 14.6 & 89 \\
\hline New South Wales (Coffs Harbour Hinterland) & NSW & $30.23-30.45^{\circ} \mathrm{S}$ & 33-1560 & 10 & 14.2 & 70 \\
\hline Sweden (Norrland) & SWD & $61.17-66.90^{\circ} \mathrm{N}$ & $25-437$ & 18 & 24.2 & 74 \\
\hline
\end{tabular}

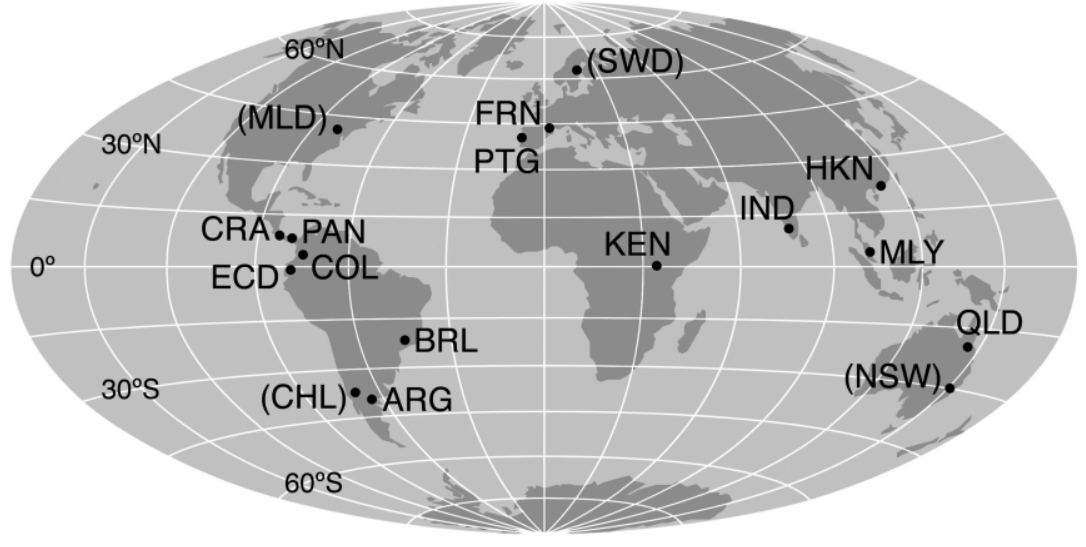

Figure 1 Location of study regions (acronyms in Table 1). Additional temperate regions are indicated in parentheses (see text and Table 1 for details).

At each site, we generally took 10 leaf litter samples, half from pools and half from riffles, from within areas of $20 ¥ 20 \mathrm{~cm}$ in a litter layer of no more than $4 \mathrm{~cm}$, using a net with a 0.5 -mm mesh, and transferred them to labelled Ziplock plastic bags. Samples were kept cool and rapidly transported to the laboratory, where they were rinsed and carefully inspected. All macroinvertebrates retained on a $250-\mathrm{mm}$ screen were removed and preserved in $70 \%$ ethanol. The number of plant species in leaf litter samples was estimated by visually distinguishing morphospecies (local botanists were consulted when necessary), and leaf litter was then dried to constant weight $\left(60-80^{\circ} \mathrm{C}\right.$ for at least $\left.48 \mathrm{~h}\right)$ and weighed. Invertebrates were separated into morphospecies (identified to species when possible), counted and classified as shredders or non-shredders based on gut content analysis following Cheshire et al. (2005). We assumed that congeneric species found in different regions belonged to different species.

At each site, we recorded the latitude (degrees from the equator) and altitude (m a.s.l.) with a GPS. When possible, we measured water temperature $\left({ }^{\circ} \mathrm{C}\right)$, conductivity $\left(\mathrm{mS} \mathrm{cm}^{-1}\right)$, dissolved oxygen saturation (\%), $\mathrm{pH}$, alkalinity (mg $\mathrm{CaCO}_{3} \mathrm{l}^{-1}$ ), total nitrogen $\left(\mathrm{mg} \mathrm{l}^{-1}\right)$, total phosphorus $\left(\mathrm{mg} \mathrm{l}^{-1}\right)$, wetted stream width (mean derived from six cross sections) and water depth (cm; measured every $0.5 \mathrm{~m}$ across the cross sections). We also visually estimated the percentage of substrate covered by leaf litter, the percentage of pool habitat, the percentage of canopy cover and the number of riparian tree species. Finally, we used 1:50,000 maps to estimate catchment area $\left(\mathrm{km}^{2}\right)$ and the percentage of native forest in the catchments. 
Because of the relatively small number of high-latitude sites surveyed, we compiled four additional data sets from temperate regions, to check for consistency with the patterns observed in our survey. Two of these regions conformed to the present global study (sampling methods described above) but were not included in the main data set because of the small number of sites surveyed: Chile (five sites) and New South Wales (Australia; six sites). Data from Maryland (USA) were taken from nine sites randomly selected from 84 described by Swan et al. (2009) and data from Sweden were taken from nine sites randomly selected from 23 described by Jonsson et al. (2001).

\section{Statistical analyses}

We evaluated shredder diversity as the number of species at each site (a), the total number of species in each region (g) and the change in assemblage composition among sites within regions $\left(b=g / a_{m}, a_{m}\right.$ being the mean a for each region; Baselga, 2010). Gamma diversity was estimated using jackknife resampling procedures [first-order jackknife estimator $=\mathrm{g}_{0}+$ $\mathrm{a}_{\mathrm{m}}(n-1) / n$, where $\mathrm{g}_{0}$ is the observed number of species in each region and $n$ is the number of sites sampled in each region; Palmer, 1990] in the pc-ord package (McCune \& Mefford, 2006), to be used in further analysis and to assess the efficiency of our survey.

Variation in shredder diversity (a-, g- and b-diversity) with latitude was explored by linear regression. As altitude was variable among regions, we removed its effect by using the residuals of the regression altitude versus latitude in the analyses, rather than latitude itself. We also examined the relationship between g- and a-diversity by linear regression. The mean a for each region $\left(\mathrm{a}_{\mathrm{m}}\right)$ was used in this analysis to avoid pseudoreplication (Soininen et al., 2009). We examined the data for curvilinearity or a decreasing slope by including a quadratic term in the regression, as an indication of $\mathrm{a}_{\mathrm{m}}$ approaching some limit that would suggest species saturation (see Shurin et al., 2000). Akaike's information criterion (AIC) was used to select the model that best fitted the data; it was calculated using the formula AIC $=n ¥ \ln (\mathrm{RSS} / n)+2 K$, where $n$ is sample size, RSS is the residual sum of squares and $K$ is the number of parameters in the model. We sought differences in species saturation between temperate and tropical zones (defined here as $>23^{\circ} \mathrm{N}$ or $\mathrm{S}$ and S $23^{\circ} \mathrm{N}$ or $\mathrm{S}$, respectively) by exploring this relationship separately for the two zones, including the four additional temperate regions (see Field and laboratory work and Table 1 ). We used the AIC to assess whether the data better conformed to a linear or a quadratic relationship in each case.

Correlation analysis was used to explore the relationship between environmental factors and shredder diversity, as several gaps in the environmental data set precluded multiple regression analysis. Relationships with a-diversity were explored at the site scale (the range of $n$ was 54 to 112, depending on availability of environmental factors), while relationships with g- and b-diversity were explored at the region scale (range of $n$ was 6 to 13$)$.

\section{RESULTS}

We found a total of 122 shredder morphospecies in the 13 main regions, with $0-10$ species per site $(\mathrm{a}=4.61$ ! $0.26 \mathrm{SE})$ and $2-22$ species per region ( $\mathrm{g}=9.38$ ! $1.71 \mathrm{SE}$ ). The four additional temperate regions had 44 morphospecies in total, with 0-9 species per site $(\mathrm{a}=4.66$ ! $0.49 \mathrm{SE}$ ) and 3-18 species per region ( $g=11.00$ ! $3.14 \mathrm{SE}$ ). Jackknife estimates suggested that we recorded on average $90 \%$ ( $\mathbf{I}$ 3\% SE) of the species present in each region at the time of sampling, or $86 \%$ ( \ 3\% SE) when additional sites were included (Table 1).

Linear regression showed that a-diversity increased with latitude ( $\mathrm{a}=4.6+0.091 ¥$ latitude; $r^{2}=0.22, P<0.0001$; Fig. 2a). When the four additional temperate sites were included in the analysis, the relationship was similar ( $\mathrm{a}=4.8+0.072 ¥$ latitude; $\left.r^{2}=0.22, P<0.0001\right)$. Gamma diversity showed no latitudinal pattern ( $g=9.5+0.029 ¥$ latitude; $r^{2}<0.01, P=0.83$; Fig. $2 b$ ), with a similar outcome when the four additional temperate sites were included ( $\mathrm{g}=11.5+0.127 ¥$ latitude; $r^{2}=0.09, P=0.23$ ). The relationship between b-diversity and latitude was not significant ( $\mathrm{b}=2.4-0.032 ¥$ latitude; $r^{2}=0.16, P=0.17$; Fig. $2 \mathrm{c}$ ); variability of b-diversity was higher at lower latitudes, but this apparent pattern disappeared when the four additional temperate sites were included in the analysis ( $\mathrm{b}=2.8-0.0005 ¥$ latitude; $\left.r^{2}<0.01, P=0.98\right)$.

Gamma and a-diversity were directly related [linear relationship: $\mathrm{a}_{\mathrm{m}}=1.81+0.28 ¥ \mathrm{~g}$; quadratic relationship: $\mathrm{a}_{\mathrm{m}}=2.66+$ $\left.0.35 ¥ g-0.34 ¥(g-10.7)^{2}\right]$. Both relationships were significant (linear: $P=0.007$; quadratic: $P=0.0001$ ), but the quadratic model explained more of the total variance (linear: 54\%; quadratic: 89\%) and had a smaller AIC (linear: 20.9; quadratic: 10.3). When analysed separately, tropical and temperate zones showed distinct tendencies. For temperate regions, the quadratic model explained slightly more of the variance (linear: 58\%; quadratic: 69\%), but the linear model had a slightly smaller AIC (linear: 12.5; quadratic: 14.6) (Fig. 3a). For tropical regions, the quadratic model explained more variance (linear: 54\%; quadratic: 87\%) and had a smaller AIC (linear: 15.2; quadratic: 7.9) (Fig. 3b).

Several local habitat variables were correlated with a-diversity: water temperature $(r=-0.53, P<0.0001)$, water depth $(r=-0.45, P<0.0001)$, stream width $(r=-0.33$, $P=0.0003)$ and percentage of substrate covered by leaf litter ( $r=-0.27, P=0.034$ ). Gamma and b-diversity showed no relationship with any of the environmental variables.

\section{DISCUSSION}

Our results suggest that global patterns of shredder diversity are complex and depend on spatial scale, as demonstrated for other organisms (Rahbek, 2005). However, we can draw several conclusions that have important ecological implications. Firstly, we have shown that the number of shredder species present at a given site (a-diversity) increases with latitude, confirming previous suggestions (Boyero et al., 2009). This implies that tropical streams have a higher risk of losing key species or the whole 
(a)

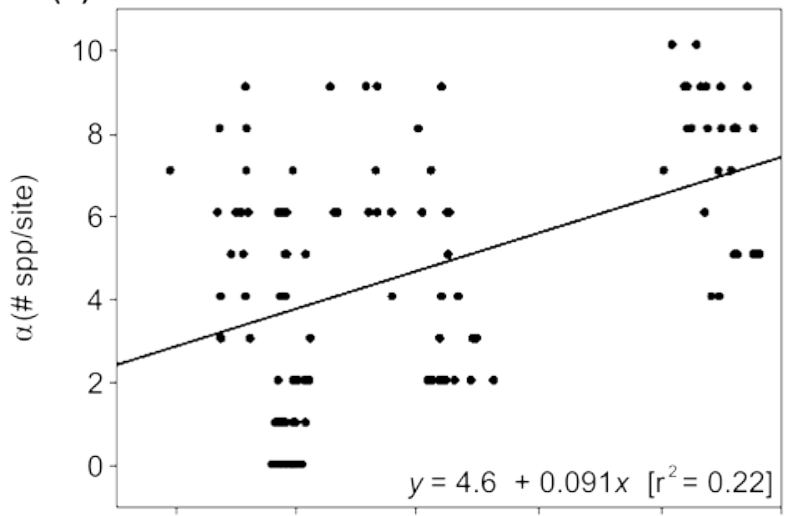

(b)

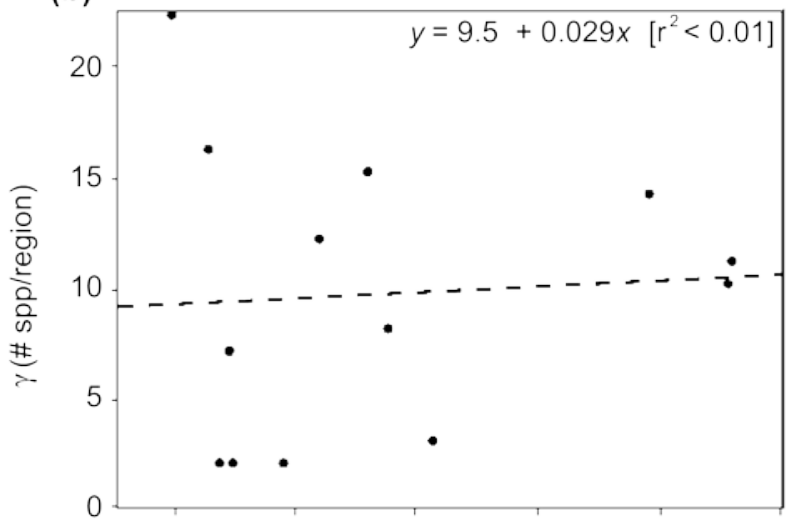

(c)

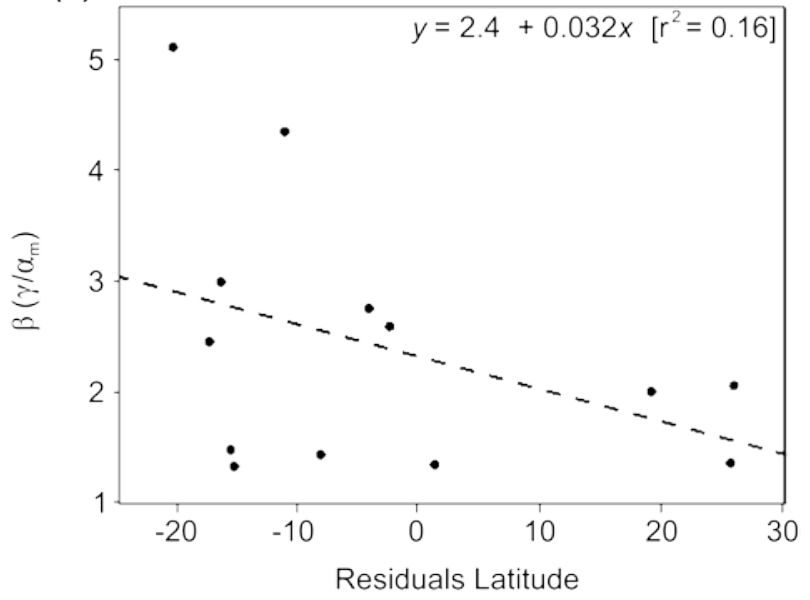

Figure 2 Linear regressions showing latitudinal variation in (a) alpha (b) gamma and (c) beta diversity ( $\mathrm{b}=\mathrm{g} / \mathrm{a}_{\mathrm{m}}, \mathrm{a}_{\mathrm{m}}$ being the mean a-diversity for each region) of shredders. To normalize for altitudinal effects, the residuals of the regression altitude versus latitude were used as predictor variable instead of latitude. Dashed regression lines: $P>0.05$.

shredder guild, which may have serious consequences for stream ecosystem functioning, including slowed leaf litter decomposition (Jonsson \& Malmqvist, 2000; Boyero et al., 2007, 2011; Dudgeon \& Gao, 2010), poor trophic transfer from the main basal resource (leaf litter) to higher trophic levels (Duffy (a)

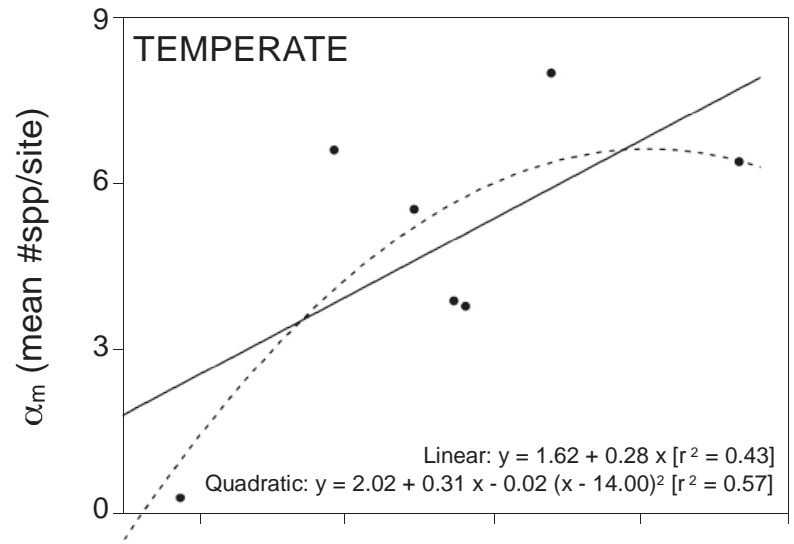

(b)

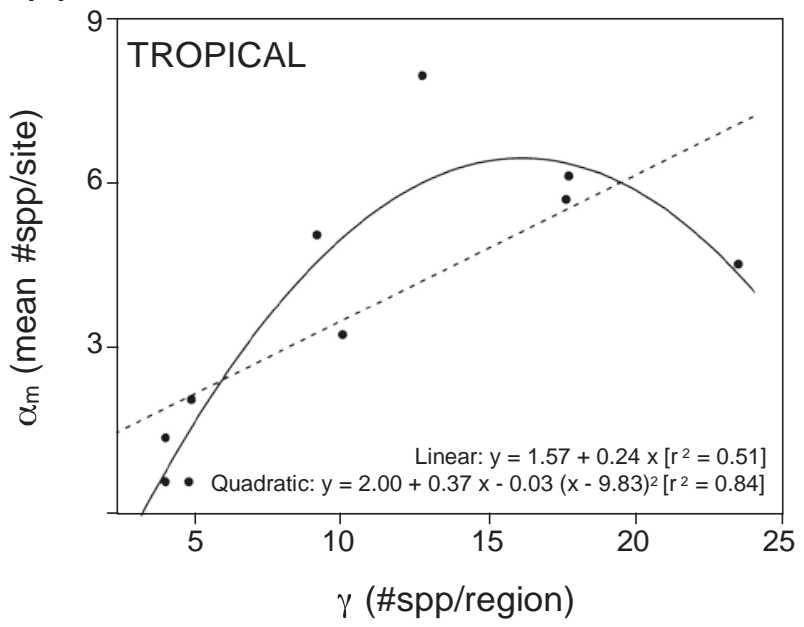

Figure 3 Linear and quadratic models exploring the relationship between regional diversity and the mean alpha diversity for each region in (a) temperate and (b) tropical regions. Because of the lower number of temperate than tropical regions surveyed, four additional temperate regions [Chile, New South Wales (Australia), Maryland (USA) and Sweden] are included in (a) (see text for details). For temperate regions, the quadratic model explained slightly more of the variance, but the linear model had a slightly smaller AIC (linear: 12.5; quadratic: 14.6). For tropical regions, quadratic model explained more variance and had a smaller AIC (linear: 15.2; quadratic: 7.9).

et al., 2007) or disruption of the processing chain (sensu Heard, 1994).

Secondly, we found that the relation between regional and local diversity differed for temperate and tropical regions. For the tropical assemblages only, we found an upper limit to a-diversity, regardless of g-diversity. This indicates species saturation, which could explain why the latitudinal gradient in a-diversity that we observed was not accompanied by a gradient in g-diversity. Shredder a-diversity seems to be limited at tropical sites by local factors such as environmental constraints or competitive species interactions (Caley \& Schluter, 1997; Heino, 2009). Alpha diversity correlated with several local habitat variables (water depth, channel width, water temperature) that 
relate to position in river networks and reflect the expected distributional pattern, with shredders being most prevalent in small streams (Vannote et al., 1980). High temperatures might limit the presence of certain shredder taxa at tropical lowland sites (Camacho et al., 2009; Yule et al., 2009) because many of them have evolved in cool waters (Fochetti \& Tierno de Figueroa, 2008; de Moor \& Ivanov, 2008). However, the lack of a clear relationship between shredder diversity and most environmental factors is likely to reflect the importance of multiple factors operating simultaneously at local scales and that are difficult to pinpoint given the broad spatial extent of the present study.

A potential local limiting factor of a-diversity at tropical sites is the existence of strong competitive interactions. This is possible, for example, if resources are limited in terms of the amount, quality and timing of leaf litter inputs. Even though seasonality exists in the tropics, the temporal pattern of leaf fall is much more even than in the temperate zone, lacking the highly pulsed and temporally predictable inputs typical of temperate streams (Cummins, 1974). As a result, leaf litter tends to be more abundant in temperate streams at a particular time of the year, and thus may allow a greater number of shredder species to coexist. Moreover, the leaves of many tropical plants contain high levels of deterrents (Coley \& Barone, 1996; Coq et al., 2010; Graça \& Cressa, 2010), so palatable leaves are often a scarce resource, notwithstanding that some tropical trees produce high-quality leaves as well (Graça et al., 2001). Thus, tropical streams tend to have less leaf litter of good quality available at any particular time than temperate streams, exacerbating competitive interactions among shredder species (Bastian et al., 2008). Different shredder species show preferences for leaves of the same plant species (Graça et al., 2001; Bastian et al., 2007), and competition is an important mechanism regulating the consumption of leaf litter by shredders (Bastian et al., 2008). Competitively dominant species feed on the preferred leaves, while other species are forced to feed on other, less palatable, leaves, which may affect their growth and reproductive success (Bastian et al., 2008; Gessner et al., 2010). Competition for a scarce resource could then limit the number of shredder species coexisting at tropical sites.

Another potential explanation for the curvilinear relationship between regional and local species richness in the tropics is limitation for dispersal among sites. This could be due to the existence of more effective geographical barriers (which is unlikely) or to a lower dispersal ability of tropical shredders. Most temperate shredders are larvae of insect taxa (e.g. caddisflies, stoneflies) with flying adult stages. Although the dispersal ability of adult caddisflies and stoneflies is often limited (Kovats et al., 1996; Griffith et al., 1998), it is higher than that of other shredder taxa such as crustaceans and molluscs, which lack flying stages altogether. The latter taxa are better represented in the tropics, where they comprised $15 \%$ of all shredder species collected in our survey, compared with only $6 \%$ in temperate regions. Consequently, although the effect is unlikely to be large, dispersal limitation might have contributed to the greater regional saturation tendency we observed for shredders in the tropics.
Our global-scale study indicates that loss of shredder species might be more critical at tropical sites, where fewer shredder species are present and the loss of key species or the whole shredder guild is therefore more likely. The lack of a latitudinal trend in g-diversity that we observed suggests that, counter to common perceptions, diversity of regional shredder species pools is similar across latitudes. Local extinctions of shredder taxa, for example in response to climate warming, might therefore be compensated by colonization of other species from regional species pools that were not locally present before. This would be more likely if the colonizers were previously absent because they were competitively inferior to the species that went locally extinct. However, limited dispersal ability of shredders lacking an adult flying stage, including some taxa typical of tropical streams, suggests that colonization from adjacent sites following local extinctions may not be the norm. Furthermore, many shredder taxa belong to mostly cool-adapted taxa, and may be close to their thermal maxima in the tropics, where predicted extinctions from climate warming may have disproportionately greater effects (Dillon et al., 2010). Given their limited local diversity, tropical shredder assemblages would thus merit special scientific attention and conservation effort, to determine or create refugia to prevent species losses and consequent alteration of stream ecosystem functioning.

\section{ACKNOWLEDGEMENTS}

The study was supported by a grant from the National Geographic Society's Committee for Research and Exploration (grant number 7980-06 to Luz Boyero) and various national funding sources. C. Canhoto, Z. Dewson, G. Cabarcas, M. Dunfee, B. Gao, Y. González, M. Hirose, P. Lisle, N. Mochizuki, D. Nawa, L. C. Y. Ng, P. Rosa, R. Sánchez-Argüello and K. Schmidt assisted with field work. J. Hortal provided statistical advice. We thank M. Jonsson, who provided latitudes for the Swedish sites, and the Maryland Department of Natural Resources Monitoring and Non-tidal Assessment Division for the provision of data.

\section{REFERENCES}

Baselga, A. (2010) Partitioning the turnover and nestedness components of beta diversity. Global Ecology and Biogeography, 19, 134-143.

Bastian, M., Boyero, L., Jackes, B. \& Pearson, R.G. (2007) Leaf preferences by shredders in tropical streams. Journal of Tropical Ecology, 23, 219-229.

Bastian, M., Pearson, R.G. \& Boyero, L. (2008) Effects of diversity loss on ecosystem function across trophic levels and ecosystems: a test in a detritus-based tropical food web. Austral Ecology, 33, 301-306.

Boyero, L., Pearson, R.G. \& Bastian, M. (2007) How biological diversity influences ecosystem function: a test with a tropical stream detritivore guild. Ecological Research, 22, 551-558.

Boyero, L., Ramírez, A., Dudgeon, D. \& Pearson, R.G. (2009) Are tropical streams really different? Journal of the North American Benthological Society, 28, 397-403. 
Boyero, L., Pearson, R.G., Gessner, M.O. et al. (2011) A global experiment suggests climate warming will not accelerate litter decomposition in streams but might reduce carbon sequestration. Ecology Letters, 14, 289-294.

Caley, M.J. \& Schluter, D. (1997) The relationships between local and regional diversity. Ecology, 78, 70-80.

Camacho, R., Boyero, L., Cornejo, A., Ibáñez, A. \& Pearson, R.G. (2009) Local variation in shredder distribution can explain their oversight in tropical streams. Biotropica, 41, 625632.

Cheshire, K., Boyero, L. \& Pearson, R.G. (2005) Food webs in tropical Australian streams: shredders are not scarce. Freshwater Biology, 50, 748-769.

Coley, P.D. \& Barone, J.A. (1996) Herbivory and plant defenses in tropical forests. Annual Review of Ecology and Systematics, 27, 305-335.

Coq, S., Souquet, J.M., Meudec, E., Cheynier, V. \& Hättenschwiler, S. (2010) Interspecific variation in leaf litter tannins drives decomposition in a tropical rain forest of French Guiana. Ecology, 91, 2080-2091.

Cummins, K.W. (1974) Structure and function of stream ecosystems. BioScience, 24, 631-641.

Cummins, K.W., Petersen, R.C., Howard, F.O., Wuycheck, J.C. \& Holt, V.I. (1973) The utilization of leaf litter by stream detritivores. Ecology, 54, 336-345.

Dangles, O. \& Malmqvist, B. (2004) Species richnessdecomposition relationships depend on species dominance. Ecology Letters, 7, 395-402.

Dillon, M.E., Wang, G. \& Huey, R.B. (2010) Global metabolic impacts of recent climate warming. Nature, 467, 704-706.

Dudgeon, D. \& Gao, B.W. (2010) Biodiversity and ecosystem functioning in a species-poor guild: a test using tropical stream detritivores. Hydrobiologia, 652, 329-336.

Duffy, J.E. (2009) Why biodiversity is important to the functioning of real-world ecosystems. Frontiers in Ecology and the Environment, 7, 437-444.

Duffy, J.E., Cardinale, B.J., France, K.E., McIntyre, P.B., Thébault, M. \& Loreau, M. (2007) The functional role of biodiversity in ecosystems: incorporating trophic complexity. Ecology Letters, 10, 522-538.

Fochetti, R. \& Tierno de Figueroa, J.M. (2008) Global diversity of stoneflies (Plecoptera; Insecta) in freshwater. Hydrobiologia, 595, 365-377.

Gaston, K.J. (2000) Global patterns in biodiversity. Nature, 405, 220-227.

Gessner, M.O., Swan, C.M., Dang, C.K., McKie, B.G., Bardgett, R.D., Wall, D.H. \& Hättenschwiler, S. (2010) Diversity meets decomposition. Trends in Ecology and Evolution, 25, 372-380.

Graça, M.A.S. (2001) The role of invertebrates on leaf litter decomposition in streams - a review. International Review of Hydrobiology, 86, 383-393.

Graça, M.A.S. \& Cressa, C. (2010) Leaf quality of some tropical and temperate tree species as food resource for stream shredders. International Review of Hydrobiology, 95, 27-41.

Graça, M.A.S., Cressa, C., Gessner, M.O., Feio, M.J., Callies, K.A. \& Barrios, C. (2001) Food quality, feeding preferences, sur- vival and growth of shredders from temperate and tropical streams. Freshwater Biology, 46, 947-957.

Griffith, M.B., Barrows, E.M. \& Perry, S.A. (1998) Lateral dispersal of adult aquatic insects (Plecoptera, Trichoptera) following emergence from headwater streams in forested Appalachian catchments. Annals of the Entomological Society of America, 91, 195-201.

Heard, S.B. (1994) Processing chain ecology: resource condition and interspecific interactions. Journal of Animal Ecology, 63, 451-464.

Heino, J. (2009) Biodiversity of aquatic insects: spatial gradients and environmental correlates of assemblage-level measures at large scales. Freshwater Reviews, 2, 1-29.

Heino, J., Muotka, T. \& Paavola, R. (2003) Determinants of macroinvertebrate diversity in headwater streams: regional and local influences. Journal of Animal Ecology, 72, 425-434.

Hieber, M. \& Gessner, M.O. (2002) Contribution of stream detrivores, fungi, and bacteria to leaf breakdown based on biomass estimates. Ecology, 83, 1026-1038.

Hillebrand, H. (2004) On the generality of the latitudinal diversity gradient. The American Naturalist, 163, 192-211.

Hillebrand, H. \& Matthiessen, B. (2009) Biodiversity in a complex world: consolidation and progress in functional biodiversity research. Ecology Letters, 12, 1405-1419.

Jonsson, M. \& Malmqvist, B. (2000) Ecosystem process rate increases with animal species richness: evidence from leafeating, aquatic insects. Oikos, 89, 519-523.

Jonsson, M., Malmqvist, B. \& Hoffsten, P. (2001) Leaf litter breakdown rates in boreal streams: does shredder species richness matter? Freshwater Biology, 46, 161-171.

Kovats, Z., Ciborowski, J. \& Corkum, L. (1996) Inland dispersal of adult aquatic insects. Freshwater Biology, 36, 265-276.

McCune, B. \& Mefford, M.J. (2006) PC-ORD. Multivariate analysis of ecological data, Version 5.10. MjM Software, Gleneden Beach, OR, USA.

Marchant, R., Ryan, D. \& Metzeling, L. (2006) Regional and local species diversity for lotic invertebrates across multiple drainage basins in Victoria. Marine and Freshwater Research, 57, 675-684.

Mills, L.S., Soulé, M.E. \& Doak, D.F. (1993) The keystonespecies concept in ecology and conservation. BioScience, 43, 219-224.

Mittelbach, G.G., Schemske, D.W., Cornell, H.V. et al. (2007) Evolution and the latitudinal diversity gradient: speciation, extinction and biogeography. Ecology Letters, 10, 315-331.

de Moor, F.C. \& Ivanov, V.D. (2008) Global diversity of caddisflies (Trichoptera: Insecta) in freshwater. Hydrobiologia, 595, 393-407.

Palmer, M.W. (1990) The estimation of species richness by extrapolation. Ecology, 71, 1195-1198.

Pearson, R.G. \& Boyero, L. (2009) Gradients in regional diversity of freshwater taxa. Journal of the North American Benthological Society, 28, 504-514.

Rahbek, C. (2005) The role of spatial scale and the perception of large-scale species-richness patterns. Ecology Letters, 8, 224239. 
Sale, P.F. (1977) Maintenance of high species diversity in coral reef fish communities. The American Naturalist, 111, 337-359.

Short, R.A. \& Maslin, P.E. (1977) Processing of leaf litter by a stream detritivore: effect on nutrient availability to collectors. Ecology, 58, 935-938.

Shurin, J.B., Havel, J.E., Leibold, M.A. \& Pinell-Alloul, B. (2000) Local and regional zooplankton species richness: a scaleindependent test for saturation. Ecology, 81, 3062-3073.

Soininen, J., Heino, J., Kokocinski, M. \& Muotka, T. (2009) Local-regional diversity relationship varies with spatial scale in lotic diatoms. Journal of Biogeography, 36, 720-727.

Swan, C.M., Brown, B.L. \& DePalma, C.A. (2009) Identifying the relative importance of leaf versus shredder species loss on litter decomposition in streams. International Review of Hydrobiology, 94, 452-471.

Vannote, R.L., Minshall, G.W., Cummins, K.W., Sedell, J.R. \& Cushing, C.E. (1980) The river continuum concept. Canadian Journal of Fisheries and Aquatic Sciences, 37, 130-137.

Vinson, M.A. \& Hawkins, C.P. (2003) Broad-scale geographical patterns in local stream insect genera richness. Ecography, 26, 751-767.

Wallace, J.B. \& Webster, J.R. (1996) The role of macroinvertebrates in stream ecosystem function. Annual Review of Entomology, 41, 115-139.

Wallace, J.B., Webster, J.R. \& Cuffney, T.F. (1982) Stream detritus dynamics: regulation by invertebrate consumers. Oecologia, 53, 197-200.

Wallace, J.B., Eggert, S.L., Meyer, J.L. \& Webster, J.R. (1997) Multiple trophic levels of a forest stream linked to terrestrial litter inputs. Science, 277, 102-104.
Willig, M.R., Kaufman, D.F. \& Stevens, R.D. (2003) Latitudinal gradients of biodiversity: pattern, process, scale, and synthesis. Annual Review of Ecology, Evolution and Systematics, 34, 273309.

Yule, C.M., Leong, M.Y., Ratnarajah, L., Schmidt, K., Wong, H.M., Pearson, R.G. \& Boyero, L. (2009) Shredders in Malaysia: abundance and richness are greater in cool highland tropical streams. Journal of the North American Benthological Society, 28, 404-415.

\section{BIOSKETCH}

Luz Boyero is a Senior Research Fellow (Ramón y Cajal Program) at the Doñana Biological Station-CSIC, Spain, and an Adjunct Principal Research Fellow at James Cook University, Australia. Her research focuses on stream ecology with special interest in global patterns of biodiversity and ecosystem functioning (particularly latitudinal gradients), and the ecology of detritus-based stream food webs. Since 2006 she has been leading the global team that conducted the present study. Author contributions: L.B. and R.G.P. conceived the study; L.B. led the research, data analysis and writing, with important inputs to data analysis and writing from R.G.P., and to writing from D.D., V.F., M.A.S.G. and M.O.G.; and all authors locally coordinated or performed research and/or commented on the manuscript.

Editor: Janne Soininen 